\title{
Cities on The Sea: A Crisis of Limits
}

\author{
CATHERINE ANN SOMERVILLE VENART \\ Dalhousie University
}

\begin{abstract}
"It is only by radically reworking the relationship between nature and culture that we can produce more progressive forms of urban society. The modification of nature is itself ... a collective project that applies the human imagination to the transformation of urban space and affirms the interdependencies that sustain a flourishing civic realm " 1
\end{abstract}

'The North Sea: Transitional Landscapes of Coexistence' was a joint interdisciplinary graduate design studio (Dalhousie + TUDelft), that focused on the future of urbanization in the transitional territory of the Rhine-Meuse-Scheldt Delta adjacent to the North Sea. In this studio students were encouraged to redefine the role of the territory linking architecture and infrastructure through concepts for 'the commons' or the collective. They developed visions for new 'urban' linkages and adapted existing infrastructures that are critical to securing urbanity in this low-lying Delta landscape, where the expected consequences of change, such as the extremes of climate, altered natures, shifting land/water borders, automation, immigration and clean energies are predicted to morphologically transform the megalopolis of tomorrow.

This paper proposes the importance of an architectural approach in linking elements and scales, articulating 'the commons' as a central and consequential space that connects the individual, the collective, infrastructure and the territory in order to address issues of change both socially and environmentally. In activating relationships between the social i.e. 'the commons,' architectural and infrastructural strategies for continued urbanization in Delta areas generally and specifically The Netherlands have potential for incremental change. Thus enabling the projection of potential solutions for the real and complex challenges facing the future of urbanization in the Delta, at the territorial scale.

\section{THE DELTA AND THE DUTCH CITY}

The Dutch Delta, originally an ecosystem of peat bogs and estuarine flows, is a resilient and fragile landscape that continually adjusts and evolves, creating a dynamic equilibrium where hydrological cycles naturally keep qualities and quantities of waters, sweet and salt, in check. The Delta ecosystem, rich in fish, fowl and malleable soil structure, made for the easy establishment of 'routes and roots'. ${ }^{2}$ Permanence, on the other hand was fraught with difficulties, whether due to flooding from rivers or inundation from the North Sea. Here, change is the permanent condition and survival demanded continued adaption and community engagement. In the Dutch Delta, 'land,' is never a given. The word land-'scape,' is itself 'formed'-land, which in Dutch land-'schop' literally is the act of shoveling 'land' against the sea. 'The Netherlands' also, as word means a land that is neither land nor water, and a land that is hard to get to. Its boundaries continually redefined; erased by floods, redrawn, and reclaimed from the sea. Constructive and destructive processes condition this long relationship between The Netherlands, the Delta and the North Sea. Where sometimes land is lost - the Biesbosch, in the St. Elizabeth's Flood (1421) - and other times won - the ljsselmeer polders reclamation (began 1950-2000). ${ }^{4}$ These traces of struggle are constructed in land, but 'deceptively' hidden within the 'landscapes' apparent cohesiveness, as 'natural' pasture or urban surface. Yet it is this history, the struggle over territory, embedded in the landscape itself, which is in actuality "...the richest historical records... we possess."

In uncovering these traces aided by maps (LIDAR, historical, and areal), a compellation of past edges, sea incursions and shifts in ecology or deltaic channels can be assembled. Here too, technological development such as, the scared lakes left from peat extraction, or the raised or indented forms of landform/water infrastructures [Dam/Dike/Polder/ Canals/Ditches, Twerp Mounds etc.], reveal change within the delta. These infrastructures, the "topographical constructions..." and the foundation of ... most cultural practices, " 6 are the base of all 'urban/cultural' form. This fact can also be traced in names; as in 'Amsterdam' formed around a dam or 'Antwerp' around a twerp-mound, each urban structure reflective of its origins, the process of its forming and growth around these infrastructures. So not only is the urban form of Dutch cities structured around these landform/water infrastructures, but the social/cultural structures that organize it through a social contract. Ensuring the maintenance of infrastructures, keeping water moving/pumping and the correct protocols, to protect the whole against its common enemy, 'water'. As early as the 12th century, this social contract became more widely organized and water boards came into being, regulating heights and putting taxes towards research for new technology. Such as the development of the 'polder,' which reclaimed land from the Sea, well into the 19th century, increasing the Netherlands' landmass by over one-third. ${ }^{7}$ Social and technological innovation went hand in hand due to necessity. 


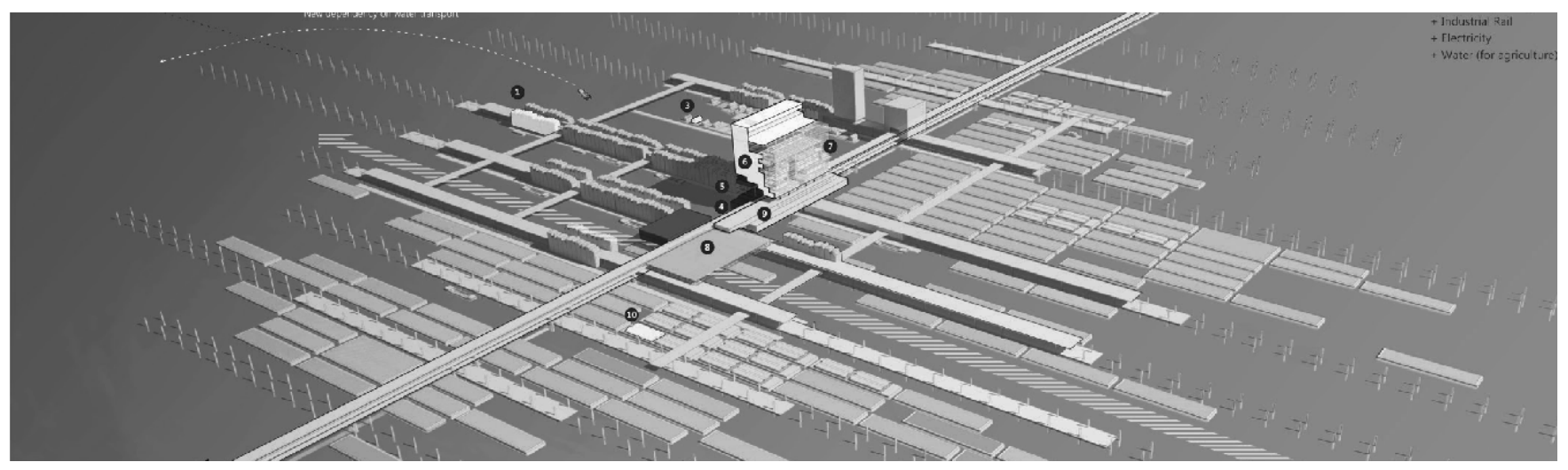

Figure 1: New Polder City, an Inter-City project between Amstrdam/Den Hague/Rotterdam and Utrecht. Ben Cotrill Dalhousie 2017

Of all the disastrous floods that occurred between 1100 and 1989 etc. the one that had the most significance was the Massive Flood of 1962. This flood caused extensive damage to all lowlands areas around the North Sea, but was most severe in The Netherlands, where greater protection was needed from the sea with two-thirds of its' urban settlements being below sea level (-.8 to -2 meters) and major cities/ports precariously positioned historically for their connection to trade 'routes' at the edge of 'land' to sea or rivers. Once again, technology would come to the rescue, resulting in the three-tiered Defense System of the Dutch Delta Program to protect the dense urban areas, and which are still in place today. It combines technological control with environmental strategies and includes: 1) Sea Gates and Sea Dikes; 2) Ring Dikes, Polders, and River Dikes; and 3) Water Storage either in lakes or temporarily in rural flood plane areas. The Defense System is continually updated by new regulations and the reintroduction of adaptive technologies, such as increases in dike heights, and expanding transnational 'grounds,' like the 'Make Room for the River Projects,' with plantings that can absorb greater amounts of water, farm twerp/mounds, allowing for greater temporary storage of water in rural areas, and the harnessing of natural processes (erosion and disposition) to protect and re-direct waters like the Sand Engine that replenishes the Dune protecting the North Sea Dike on the Western coast. These act in combination with the threetiered Defense System to protect the main urban population areas (Rotterdam, Amsterdam + Den Hague), which include the many of the main economic area.

The increased threat of shifts in water land boundaries due to sea level rise from the North Sea, and increased precipitation from intensive rain events or sudden unpredictable increases in water in rivers due to snowmelt, also threatens urban areas from within the Delta. Thus creating vulnerable populations that could again become islands states surrounded by the sea. A recent study, predicts that by 2100 , sea levels could raise up to $3-3.5$ meters instead of the 1.3-meter expected by the 'extreme scenario' of the Dutch Delta Program. ${ }^{8}$ This means that substantial areas of Holland will be temporally or fully a part of the future geography of the North Sea and much of the Dutch infrastructures will not be able to withstand these changes. This new state of the Netherlands reminds one of JG Ballard's fictitious depiction of London (Thames Estuary), in "The Drowned World" from 1962 or real proposals by M.U.D.'s Mare Meum (2005), for the Belgium coast in which a planned retreat is proposed and OMA's Zeekrafen 2050 (2009), or West 8's 'Happy Isle' (2008) proposals to expand, creating islands for energy production and recreational etc. that further protect the dense urban areas along Netherlands' west coast and the North Sea. These proposals, based on existing technologies of pier structures or deposition of topography similar to the Rotterdam port construction or the Sand Engine and twerp mounds (farm steeds), illustrate how landscape can temporally or permanently accommodate changes.

With technology enmeshed within the natural landscape of the Dutch Delta, 'nature' can be understood as artificial and all but replaced by technological mechanisms. This hybrid of 'machine' and nature suggests, "there is no such thing as either man nor nature now, only a process that produces the one within the other and couples the machines together."9 The dichotomy of nature and technology, is no more two opposing forces, but instead indistinguishably one "Cyborg Nature" where "...nature is what is taking over, both our technologies and propelling/controlling the networks, systems and processes." ${ }^{\prime 10}$ The Dutch Delta is a hybrid landscape, which has perhaps prepared the Dutch to face unpredictability through technological control, but has also removed the role of the individual and landscape to become one of the most technologically regulated 'landscapes' in the world. Consequently, the water board's control through almost fully automated processes, creates the line between land and water. This shift from individual social contracts to an isolated political entity, may perhaps need to be re-examined to reintegrate the individual and social, in order to break down the larger infrastructure and to strengthen the many smaller parts/acts that can contribute to the whole. 


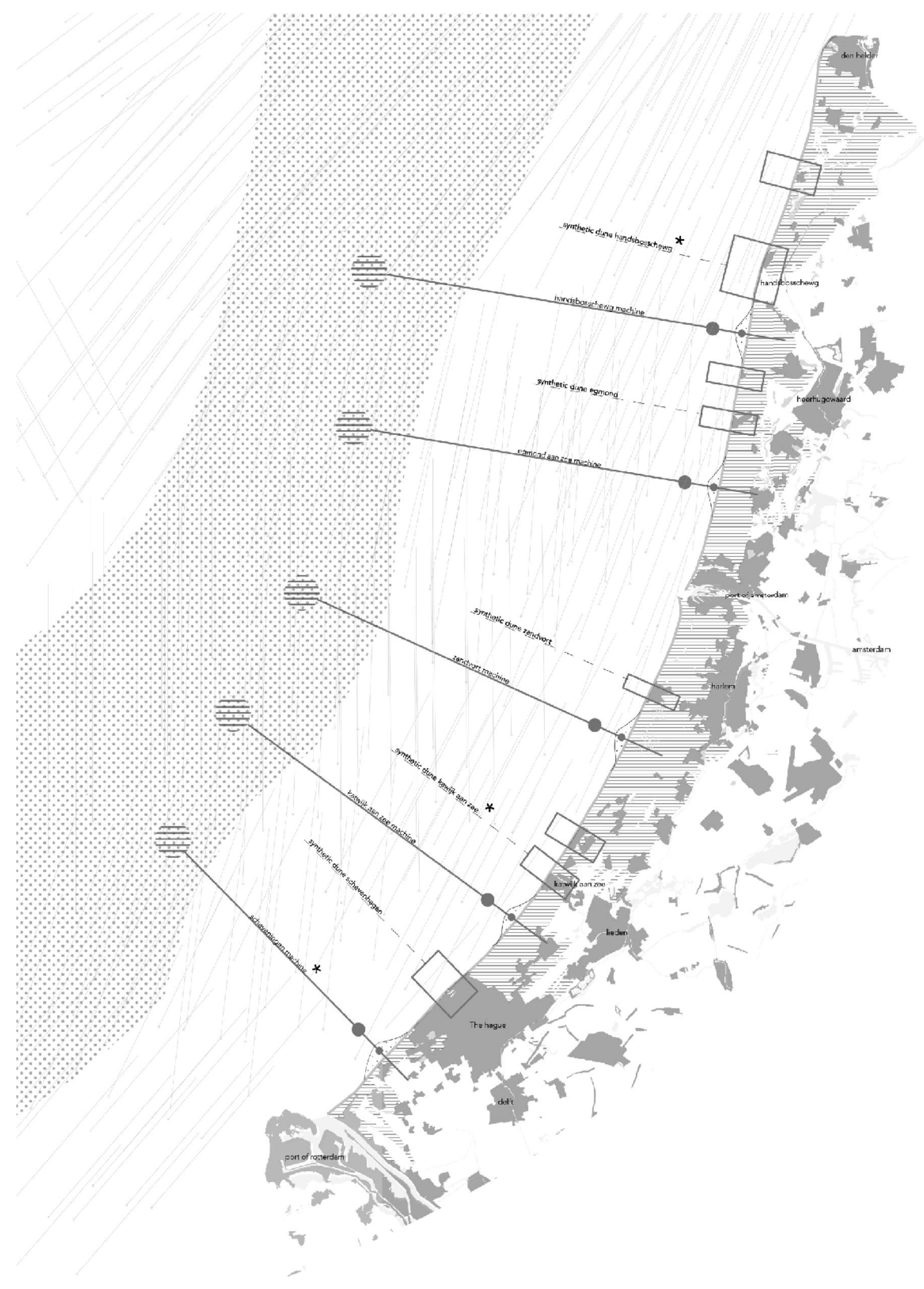

Figure 2: Mitigating Westen Edge, Automation and the Sand Engine; Map Analysis Liam Guitard Dalhousie 2017. 


\section{DESIGN METHODOLOGY}

The methodology of the studio learns from this history and various strategies, using: a) a Layered Scalar Map or Base Map to draw out and compile spatial and temporal information operating at a variety of scales; b) a Landform/Water Infrastructure and Urban Form Case Study, which connects how history, to understand systems, processes and how solutions evolve; c) Visual and Physical Surveys, builds on mapping with the existing (context, social contracts, and potential programs) d) Integration based on examples of 'The Collective Form' and previous studies to create new 'linkages' and 'The Collective'; e) Hybrid Programmatic Pairings: Technology Landscape/Nature or Infrastructural - Architecture and Unit/ Elements - Collective; and e) Scenarios, to test systems at various scales. It takes opportunities within interconnected scalar systems and processes to develop flexible linkages between existing/new elements, collective/open space, infrastructural systems and potentials within Delta dynamics. Thus creating an open ended architectural-infrastructural system that connects to both a local context and the larger territory, able to adapt to the parameters of change, in order to rethink how to re: inhabit or continue to inhabit the Delta in the future.

The Layered Scalar Map or Base Map was used to collect and integrate information at a variety of scales. Compiling information from: GIS, LIDAR, areal photographs and cartographies, both historic and current using an ecological framework of 'Patch', 'Edge' and 'Corridor' to define temporal fixity and trajectories of movement, and analyze the contexts. This allows students to understand and visualize shifts in the Delta landscape, to analyze relationships between elements, systems (urban/landform/water infrastructure) underlying historic and current cultural structures and processes both spatially, temporally as well as the larger scalar relationships of natural systems that define the territory. Linking Nature, the urban environment, infrastructure and architecture. An example of this integration of architectural-infrastructure -urban fabric can be found in Amsterdam, built around a Dam that controls water levels and flow of water through its' canal system, its' edges evolving as structural support and architectural fabric. This structural unit is flexible enough to accommodate various programmatic types from industrial, retail, to housing.

Along with the mapping, students were asked to define a Landform/Water Infrastructure [Polder; Dike; Canal; Twerp Mound] analyzing it in terms of movement/fixity and how it was integrated into other city/settlement structures/ systems/programs, and in relationship to environmental processes of the Delta (i.e. position, flow, geological edges...). They were asked to research; Historical, Technological/ Constructive and Environmental Dynamics that informed relationships between urbanity and the Delta. By asking how the infrastructure changed through time, and what the potentials might be for change further adaption. This enables students to understand the contextual, humanistic relationships, trajectories/temporal concerns and limits that would later become the basis for their future design development. Setting up a basis for their design proposals and a theoretical structure of attachment to existing urban/infrastructure both structurally and spatially, i.e. whether linear, cluster etc. and how ideas of 'the commons' could activate (programmatically) engaging both socially and environmentally.

The Visual and Physical Surveys done while in the Netherlands, develop further the first Layered Scalar Mapping. This enabled the students to revisit an area and observe first hand, the various temporal, spatial and physical dimensions or qualities: observations between patterns of movement/ corridors and nodes/intersections and how interactions/ exchanges between elements/programs [i.e. Economic; Residential; Entertainment, Institutional, Recreational/Pubic Spaces/Open Space, Harbors/Ports \&Terminals]; and linkages occur or are accessed, crossed or activated. As well it was important to see how culturally important/historic elements were incorporated into new fabric and how public space and green/open spaces are used and have developed (past to present) due to cultural or environmental pressures, which all give indications of the cycle of growth and decay in which all systems engage.

These research, observations, analysis and mapping exercises became the conceptual framework, which linked ideas of 'the collective' and ecology principles of change, with scalar intersections between architecture and infrastructure, while informing strategies for adaption at the various scales of the Delta Territory. This framework is similar to methodologies found in the work of the Metabolist's 'Collective Form' (1964), Unger's 'Grossformen' (1966), Smithson's, 'Mat-Cities' (1950-74) and Constant's New Babylon (1958-1969), which were developed after the devastation of WWII and critical of the abstraction and functionalism of modernism. It was Gideon whom suggested that Modernism was a point where a "split in human nature created through modernity between knowledge and feeling, reason and emotion, man and nature, science and religion."11 Resonating today with the remnants of modernisms' singularly defined infrastructures, urban and architectural elements, and societal changes that reinforced these singularities: creating isolation, individualistic behaviors and physical discontinuity caused by privatization of public space and large singular usage infrastructures/ builds that further fragment a sense of the city as a collective entity. The question is, how to retrofit and rebuild in the face of change? Perhaps The Collective Form (Grossformen, MatBuilding, Group Form), suggests ways to alleviate potential devastation brought on by climate and social change not so dissimilar to the destruction of war. 
Due to the cultural history and Deltaic condition of living with change with their underlying social contract, The Netherlands has the potential to implement new scenarios and test possibilities. In the studio, the examples of 'New Collectives', 'Grossformen' and 'Mat-Building,' "can be said to epitomize the ...collective; where the functions "come to enrich the fabric, and a new order based on interconnection, patterns of association and possibilities for growth, diminution and change..."12 A methodology and a set of 'case studies' were used to help students develop strategies for the 'New Collectives' and to understand relationships between linkages/movement and base elements, that structure a temporal and spatial concept with open ended implications. As such, open ended, and adaptive urban/architectural structure can

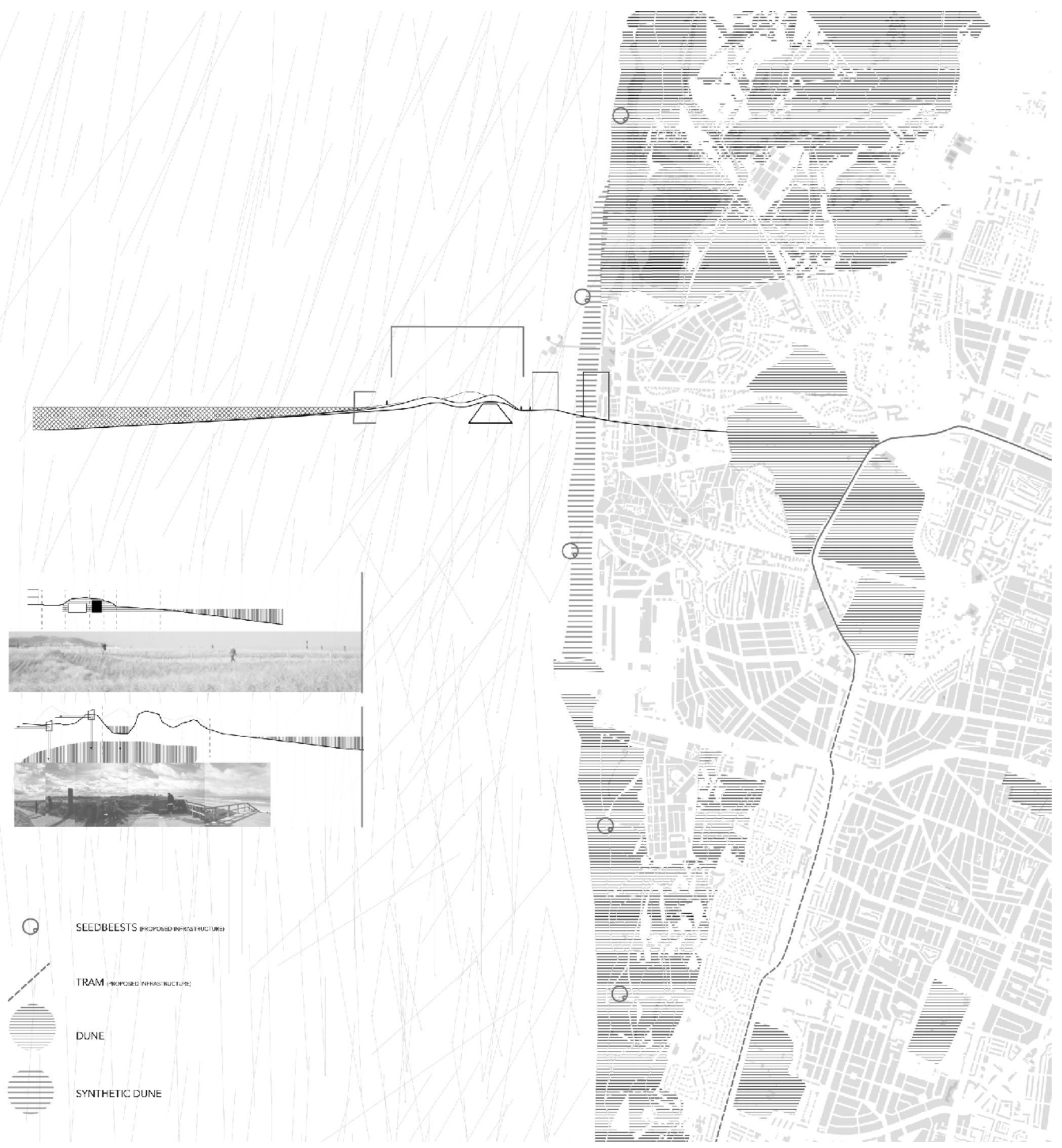

Figure 3: Partial Site Plan and Site Sections revealing site startegy. Liam Guitard Dalhousie 2017. 
be found in Constant's 'New Babylon', where a network of connecting sectors, superimposed over an elevated transportation network creating no distinction between urban and rural where it's structure could continue unending; or similarly, the Smithson's 1958 proposal for Berlin with its' elevated platforms; or the Metabolist's pattern of units/ elements linked by connectors and negotiated by collective nodes. In this way, the studio uses an architectural approach to provide linkages between elements, scales and programs whether built or suggestive, past and present, physical and abstract; and to the existing context and as contingent on change. In the context of the Dutch Delta, 'the collective' is used to connect people and territory, and can accommodate both natural and cultural programmatic considerations at different scales. It uses the existing and proposed policies, regulations, as well as the planned renewal/adaption to existing infrastructures set internally by state water boards or mandated national or European wide standards, to understand, create a proposal and test in dialogue with attitudes of either control/expand or flood/retreat, found in two proposals: i) OMA's proposal, Zeekrafen 2050 (2009), an energy ring/ recreational islands protecting urban areas; or ii) MUD's Mare Meum proposal (2005), a planned retreat.

Therefore, this design studio developed ArchitecturalInfrastructural design strategies that could maintain coherence despite the addition and subtraction of individual parts. Similar to Metabolists' architecture was a part of the "organic comprehensive whole, ${ }^{13}$ continually changing as an ecological system. The biologist Ernst Haeckel defined, ecology as "the science of relations between the organism and the surrounding outer world," ${ }^{14}$ referencing mutual relationships and the interconnectedness of things. Space and time were not conceived as absolute concepts anymore, but instead as relative and interdependent entities. It was then about forging a "new world." ${ }^{15}$

The following are examples of three student projects: 1) The New Polder City an inter-city link (figure 1), between existing urban centers. Tower elements act as markers, accommodating multi-programs that can change depending on phase or necessity. Initially evacuation housing and agriculture, in the new flooded landscape paired with a linear elevated infrastructure connector which, as this becomes the norm, is expanded to an agricultural/housing barge system and the tower becomes the public sphere of the project; 2) The Future Dune attaches to -an infrastructural 'process that builds with Nature'. The Sand Engine becomes a pro-type, questioning how to engage with an ever-new site (figures 2-4). Where an open-ended and ever shifting set of programmatic clusters deployed at particular points of weakness along the coastal

Figure 4 (right): Axo Digarms and Perspective showing deployable programs and shifting sites (Top)Seed; (Middle) Skiff and (Bottom) System. Liam Guitard Dalhousie 2017.

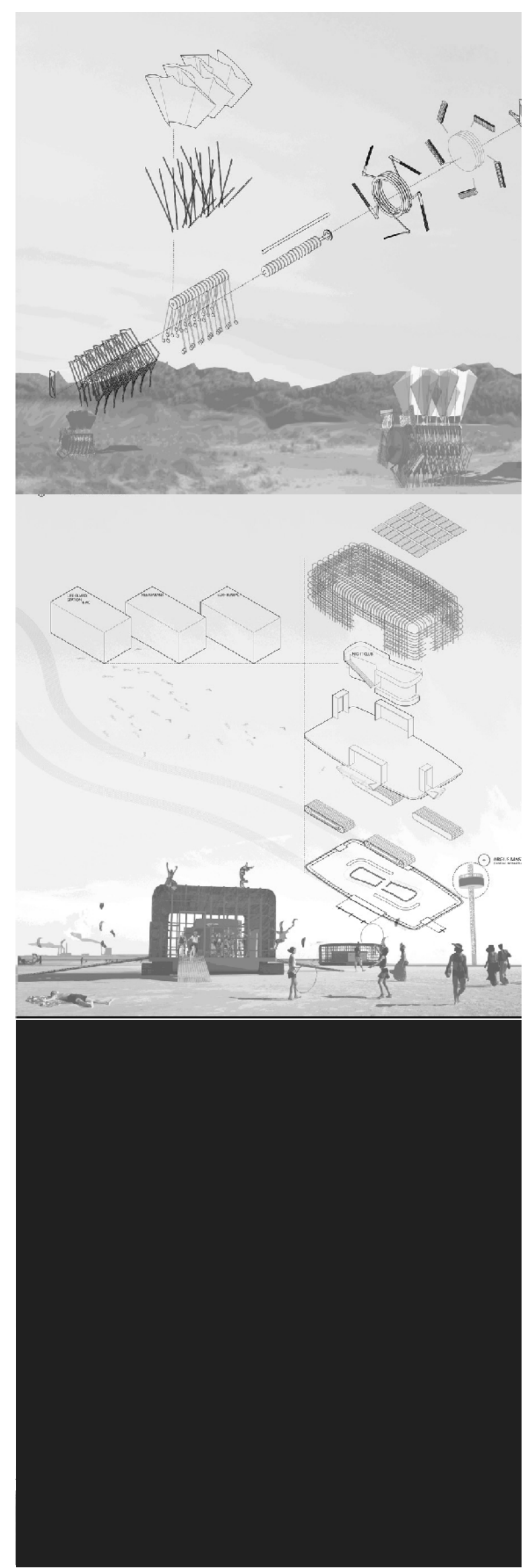




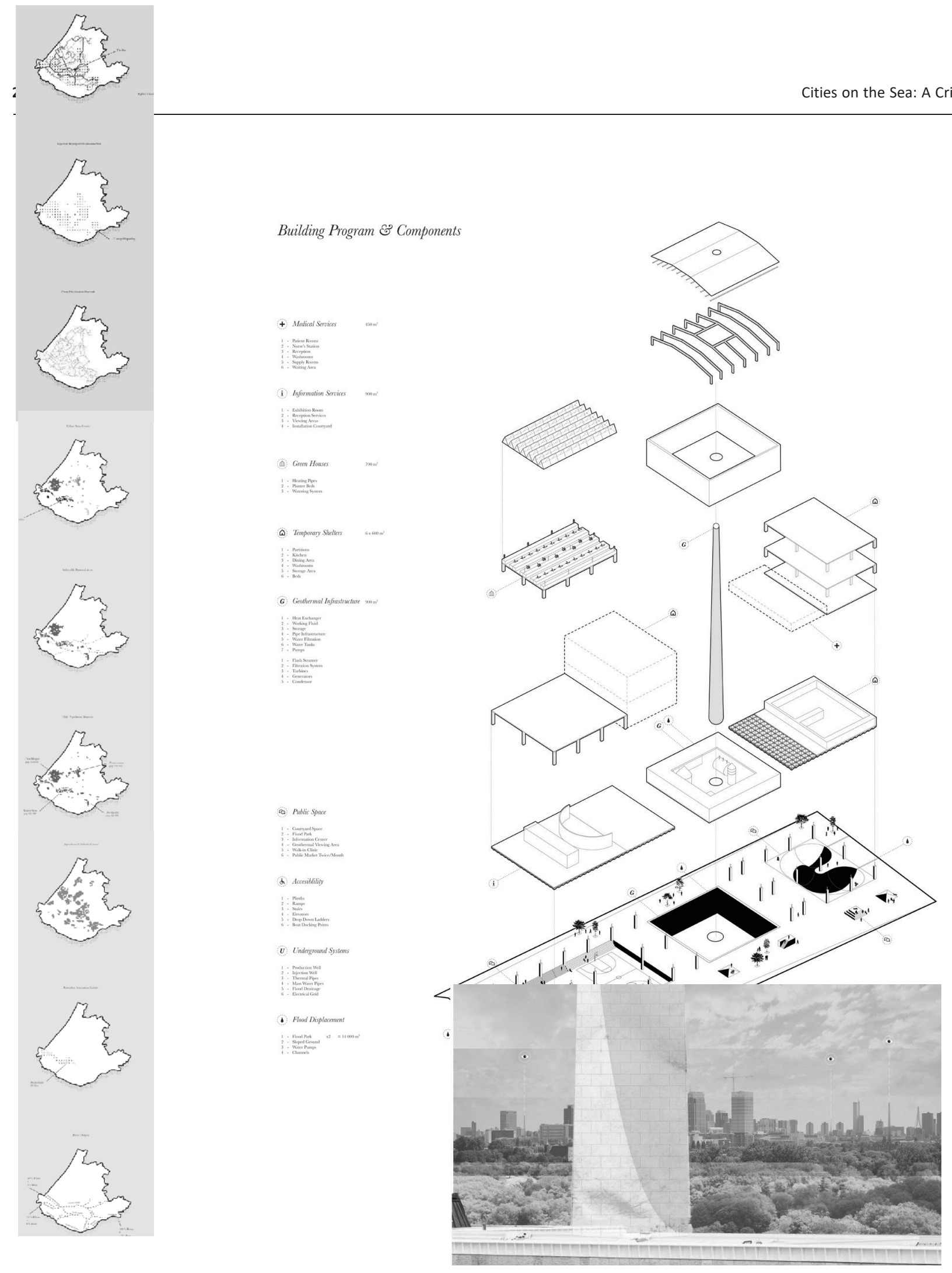

Figure 5: Investing in Energy Infrastructure as strategy for Marking The Common's \& Change, Maps and Axo drawings Stewart Lore, Dalhousie 2017 
dune/sea dike (figure 2). The inner order is based on a process of erosion and deposition that eventually influences/ facilitates the subsequent expansion and changing of a series of programmatic elements deployed along the entire North Sea coastline (figures 3-4); and 3) Investing in Energy Futures takes on the idea of the 'life cycle' of ground source energy, which could be deployed at the neighborhood scale. It uses micro energy distribution systems and energy production, paired with water storage as the seed, which becomes both a physical marker and a multi functional building/public space. Including cultural/excavation hub, a water retention/ park landscape where elements can function differently as needed (figure 5).

\section{CONCLUSION}

Underlying each projects, design strategy takes are ideas for 'the collective' and individual elements/units that operate both architecturally and infrastructurally. Acting both as place and connector within a larger open-ended system. Each is coherent as a part or whole within its inherited context and that of the larger system. This approach could be applied to various projects, scales and temporal dimensions and speculations for 'Collective Form' would have the potential to create new connectors and adapting elements that encourage further hybridization and interdisciplinary work.

Is it not our place within the Natural world is to understand the scalar relationship between various dynamic parts to the whole? ${ }^{16}$ An understanding extremely important for today's changing society and embedded in this methodology derived from 'collective form' that unites systems/urban design and architectural pedagogy. From this, students create process driven and open-ended designs that can potentially facilitate change, some we can predict and others we cannot.

\section{ENDNOTES}

1. Matthew Gandy, Concrete and Clay: Reworking Nature in New York (Cambridge: MIT Press, 2002), 5-6.

2. James Clifford, Routes: Travel and Translation in the Late Twentieth Century (Cambridge: Harvard University Press, 1997), 22.

3. John Stilgoe, What is Landscape? (Cambridge: MIT Press, 2015), 5.

4. Noel Murphy, Landwinning: Technology and Transformation in the Dutch Lowlands, 2016 http://www.noel-murphy.com/rotch/2016/06/27/ landwinning-technology-and-transformation-in-the-dutch-lowlands/.

5. W.G. Hoskins, The making of the English Landscape (London: Hodder \& Stoughton, 1955).

6. David Leatherbarrow, "Levelling Land," In Recovering Landscapes: Essays in contemporary Landscape Architecture, ed. James Corner's (Princeton Architectural Press 1999) 171

7. Angélique Melet, Benoit Meyssignac, Rafael Almar and Gonéri Le Cozannet, "Under-Estimated Wave Contribution to Coastal Sea-Level Rise," Nature, articles/s41558-018-0088-y.pdf.

8. Gilles Deleuze and Fèlix Guattari, Anti-Oedipus: Capitalism and Schizophrenia (Minneapolis: University of Minnesota Press, 1983), 42-50.

9. Donna J. Haraway Simians, Cyborgs and Women: The Reinvention of Nature (London: Free Association Books, 1991), 151.

10. Allison Smithson, "How to Recognize and read Mat-Building. Mainstream Allison Smithson, "How to Recognize and read Mat-Building. Mainstream
architecture as it developed towards mat-building," Architectural Design, architecture as
no. 9,(1974).
11. Rem Koolhaas and Bruce Mau, $S, M, L, X L$, ed. by Jennifer Sigler, (NY: The Monacli Press, 1995), 969.

12. S. Giedion, Space, Time and Architecture, (London: Oxford University Press, 1942), 762. See also p. 12-3, 760-1.

13. F. Capra, The Web of Life: a New Synthesis of Mind and Matter, (London: Flamingo Press, 1997), 29-33.

14. Aureli Pier Vittorio,"The possibility of an Absolute Architecture, "The Archipelago City and its Project, (Cambridge: MIT Press, 2011). 